\title{
Injection Moulding Tool Design Manufacturing, Estimation and Comparison of L\&T Power Box Side Panel Using Plastic Materials HDPE, ABS, PP and PC
}

\author{
N. Sreenivasulu ${ }^{1}$, Dr. D. Ravikanth ${ }^{2}$ \\ I(M. Tech Student, Dept of Mechanical Engineering, K.S.R.M College of Engg, Kadapa, Andhra Pradesh, India) \\ ${ }_{2}^{2}$ (Associate Professor, Dept of Mechanical Engineering, K.S.R.M College of Engg, Kadapa, Andhra Pradesh,
} India)

\begin{abstract}
Power box is a component which is used in earth movers. It controls the power circuit. It has top cover, front cover, back cover and side panel. The aim of the paper is to create the L\&T power box side panel by using parametric pro/E wild fire 5.0. The part modeling, Core-cavity design, CNC manufacturing programming and Mould flow analysis i.e simulation to avoid potential mould-filling problems is done by pro/E wild fire 5.0. Mould base design and Mould calculations are also done in this paper according to HASCO standards. The material selection for mould design is taken as EN31B steel. Structural analysis is done for core and cavity by using ANSYS software to know the pressure, displacement, stress results. Cost of the total die assembly and cost comparison of different plastic components (HDPE, ABS, PP, and PC) are estimated. Here the process is using in injection moulding and manufacturing a variety of parts from simple to complex components.
\end{abstract}

Keywords: Injection moulding, Mould flow analysis, plastic materials, Power box, Tool design.

\section{Introduction}

1.1Injection Moulding Injection moulding is the most common method of part manufacturing. It is a manufacturing process for producing parts for both thermoplastic and thermosetting plastic materials. The process is material is fed into a heated barrel from the hopper, mixed and forced into a mould cavity where it cools and hardens to the configuration of the mould cavity, the features of the desired part such as simple components to complex components. The advantages of injection moulding are high production rate, repeatability high tolerances, low labour cost and minimizes scrap cost but equipment investment and running cost is high.

1.2Equipment Injection moulding machine consist of a material hopper, screw type plunger or an injection ram and a heating unit. It holds the mould tool to get the required shape of the components. In which the amount of clamping force that the machine can exert in terms of in tonnage. The plastic material required more injection pressure to fill the mould and this more clamp tonnage required to hold the mould closed.

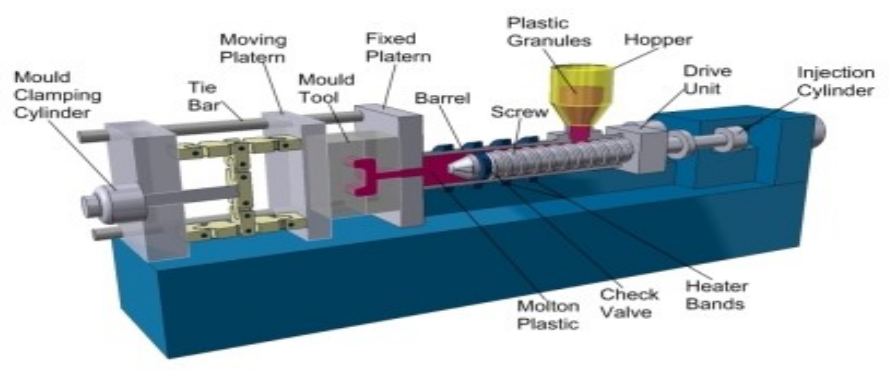

Fig. 1.1 Injection Moulding Machine

1.3Mould Mould or die are the common terms used to describe the tooling used to produce plastic parts in moulding. It is expensive to manufacturing and used in mass production. Generally the moulds are prepared by steel, aluminum and beryllium-copper alloy. The choice of material should be more parts have to be manufacturing before wearing out. Steel moulds are more cost to construct but their longer life span will offset the higher initial cost over a higher number of parts made before wearing. Moulds are manufacturing by the $\mathrm{CNC}$ milling machine. In this machine complex and more accurate moulds are prepared in less time; the selection of the milling tool bit depends on the operation and size of the work piece (mould).

1.4 Time Function The time it takes to make a product using injection moulding can be calculated by adding: 


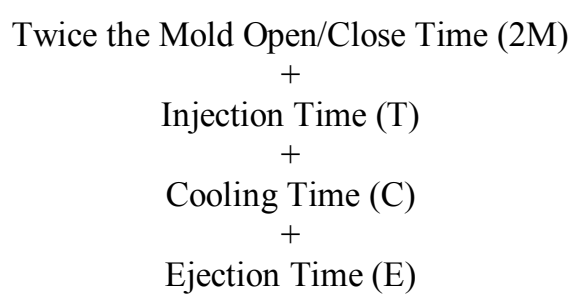

Total time $=2 \mathrm{M}+\mathrm{T}+\mathrm{C}+\mathrm{E}$

Total cycle time can be calculated by using $\mathrm{t}_{\text {cycle }}=\mathrm{t}_{\text {mould close }}+\mathrm{t}_{\text {injection }}+\mathrm{t}_{\text {cooling }}+\mathrm{t}_{\text {mould open }}+\mathrm{t}_{\text {ejection. }}$. The time taken for mould (close, open) injection, ejecting are few seconds. The cooling times, which dominate the process which takes more time one.

1.4.1Lubrication The mould must be cooled in order for the reproduction to take place because of the heat capacity, inexpensiveness and more availability of water and is used as the primary cooling agent to cool the mould. It channeled through the mould to account for quick cooling times. A colder mould is more efficient because this allows for faster cycle times.

1.5 Mould Design The mould consists of two primary components injection mould (plate A) and ejector mold (plate B). In which molten plastic enters into channels of mould through the injection barrel. Along these channels molten plastic enters into the various gates and into the cavity to form the desired shape of part. The amount of resins removed to fill the spruce, runner and cavity of a mould is a shot. Trapped air in the mould can escaped through air vents that are grinded into the parting line of the mould. Shrinkage is considered for determine the draft. The draft required for easy with drawl of the mould is dependent on the depth of cavity. If the skin is too thin, the mould cavities are touch to each other, the molten elastic will stick to the mould cavity. To avoid this and also to remove the molten part from the mould cavity ejector pin are used

1.5.1Tolerances, Surface And Shrinkage Moulding tolerance is a specified allowance on the deviation in parameters such as dimensions, shapes, weights or angles, etc. To maximize control setting tolerances there is usually a minimum and maximum limit on thickness, based on the process. Injection moulding typically is capable of tolerances equivalent to an IT Grade of about 9-14. Possible tolerance of a thermoplastic or a thermo set is \pm 0.008 to \pm 0.002 inches. Surface finishes of two to four micro inches or better are can be obtained.

Shrinkage is inherent in the injection moulding process. Shrinkage occurs because the density of polymer varies from the processing temperature to the ambient temperature. The shrinkage of moulded plastic parts can be as much as 20 percent by its volume, when measured at the processing temperature and the ambient temperature.

1.5.2Clamping Unit The clamping unit holds the mould together, opens and closes automatically and ejects the finished part. There are three types of clamping design which are toggle, hydraulic and hydro mechanical. In these hydraulic clamps are used which are more flexible than other one and in the range of 1300 to $8900 \mathrm{KN}$.

\section{Power Box}

Power box are devices that contain the wiring junctions or intersections that allow the wiring in the home or public building to interface with the main power supply provided by a local utility. The presences of the power box are generally regarded as both practical and more esthetically pleasing than a bunch of exposed wires. The main purpose of a power box is to conceal the electrical junctions from sight, usually it constructed with the use of metal or hard plastic, the general appearances of a junction box is either a square or rectangular design. It can help contain sparks in the event that one of the junction overloads and thus limit of damage is caused. Life of the electrical power box can be measured in decades. Here the power box is used in earth movers.

2.1 Material Used For Power Box Usually it is made by plastic because of highly resistant to corrosion and offer good protection against dust, fire and moisture. Different types of plastic materials are available which is Acrylonitrile-Butadiene-Styrene (ABS), High-density Polyethylene, Polycarbonate, Polypropylene and Polystyrene. For preparing the part of power box ABS plastic is used because of better conductivity, low resistance durability etc.

2.2 ABS Plastics It was first discovered during World War 2 when its basis SBR, was used for the alternatives to rubber. This material is a Terpolymer of Acrylonitrile, Butadiene and Styrene, usually composition are about 
half styrene with the balance divided between butadiene and Acrylonitrile. Features of ABS are high heat resistance, good impact resistance, high flow, good dimensional stability, flame retardant.

2.3Earth Movers Ancient roman engineer Vitruvius ( $1^{\text {st }}$ century BCE) gave detailed description of heavy equipments. Heavy equipment refers to heavy-duty vehicles; design for construction tasks involving in the earth work operations is also known construction equipment, construction plant, earth movers or engineering vehicles.

2.4 Cad and Pro-Engineer Computer-Aided Design (CAD) is the use of computer technology for the process of design and design-documentation and it is known as Computer Aided design Drafting. Pro-Engineer is the standard tool in 3D product design, featuring in industry-leading productivity tools that promote best practice in design.

Pro/Mould design is an optional module for Pro-Engineer that provides the tools to simulate the mold design process within Pro-Engineer. This module lets modify, create, and analyze the mold components and assemblies, and quickly update them to changes in the design model.

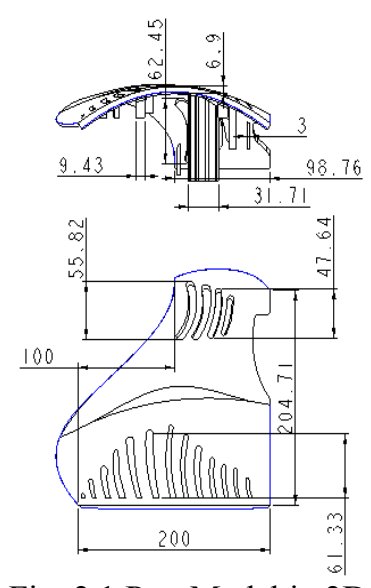

Fig. 2.1 Part Model in 2D Drawing

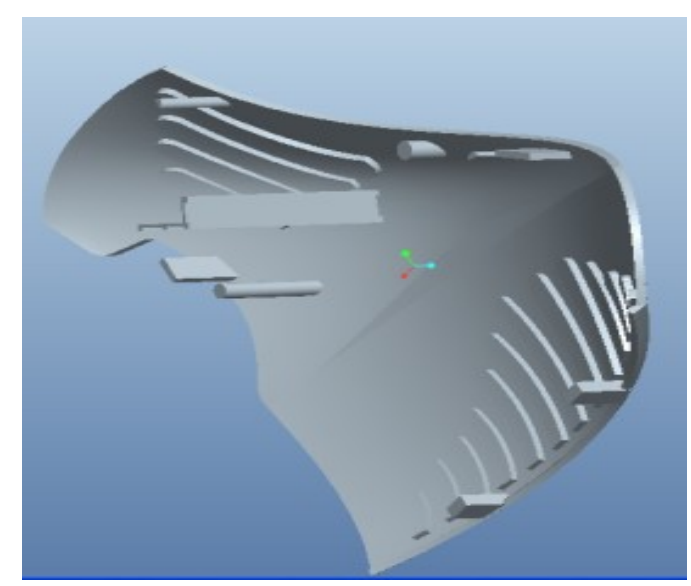

Fig. 2.2 Part Model in 3D Drawing

\section{Mould Flow Analysis}

It is 3D solid-based plastic flow simulation that allows plastics part to determine the manufacturing of their parts during the preliminary design and avoid potential mould-filling problems such as sink marks, short shots, weld lines and air traps. It optimizes the part wall thickness to achieve uniform filling patterns, lowest part cost and minimum cycle time.

3.1 Plastic Advisor In Pro-E Plastic advisor simulates mould filling for injection moulded plastic parts and it enables engineers to design for manufacturability insight-insight that can significantly reduce late-cycle design changes and mould reengineering costs.

3.1.1 Benefits To creates web reports within pro-E browser, locating best optimal injection point for reducing cycle time and improve part appearance, it access library of common plastic materials and automatically select from typical injection moulding machine parameters and also identify potential mould-filling problems.

3.2 Plastic Flow Analysis It gives the overview of the model's analysis and the flow path of the plastic actual in the mould.

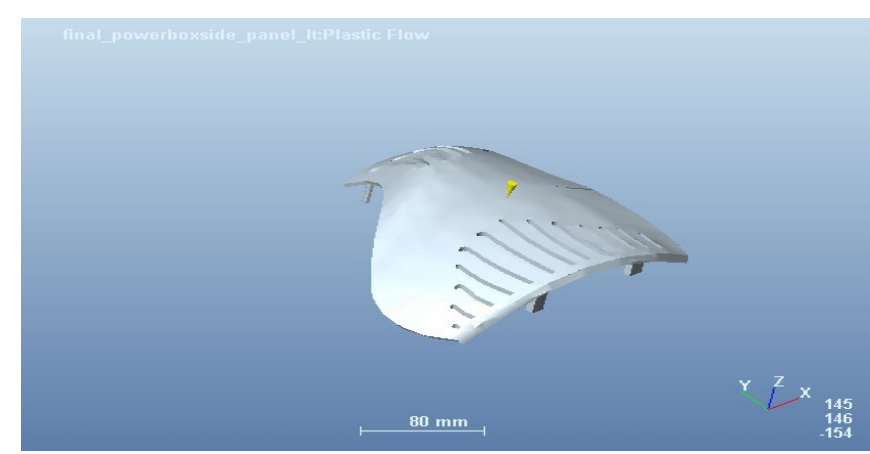

Fig. 3.1 Plastic Flow Analysis 
Full Time It shows the time filing of the complete part, which displays in a range of colors from red to indicates the first region to fill, and to blue to indicate the last region to fill. A short shot is one of the part of the model that did not fill, and will be displayed as translucent. It shows in the figure that total time taken to fill the complete part is $2.99 \mathrm{sec}$.

Confidence Of Fill It displays the probability of a region within the cavity filling with plastic at conventional injection moulding conditions. It shows the figure that confidences of fill of complete part is high.

Injection Pressure The injection pressure results is a contour plot of the pressure distribution throughout the cavity at the end of filling The total injection pressure required to fill the complete part is $27.42 \mathrm{MPa}$.

Pressure Drop It shows the pressure required to flow the material to each and every point in the cavity. The total pressure is required $27.42 \mathrm{MPa}$.

Flow Front Temperture .It uses a range of colors to indicate the region of lowest temperture (coloured blue) through to the region highest temperature(coloured red). The coloured shows the material temperture at each point as that point was filled. It shows the changes in the temperature (i.e 225.41 to 153.27 deg.C) of the flow front during filling.

Quality Prediction The Quality display is derived from combinations of the three colors listed as unacceptable (red), acceptable (yellow) and preferred (green). In Figure shows that some area is yellow color and remaining as in green.

Air Traps Unique location of a injection point was not found corretly then Air Traps are found in the part.

Weld Lines It is the line where two flow front meets which each other in mould process. Due to weld line or meld line that area will be weak one. It is causes due to injection speed is too low, small injection gates etc.

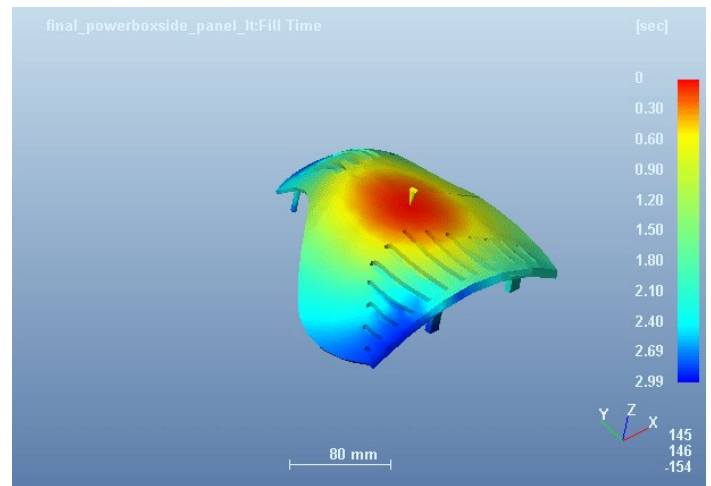

Fig. 3.2 Full Time

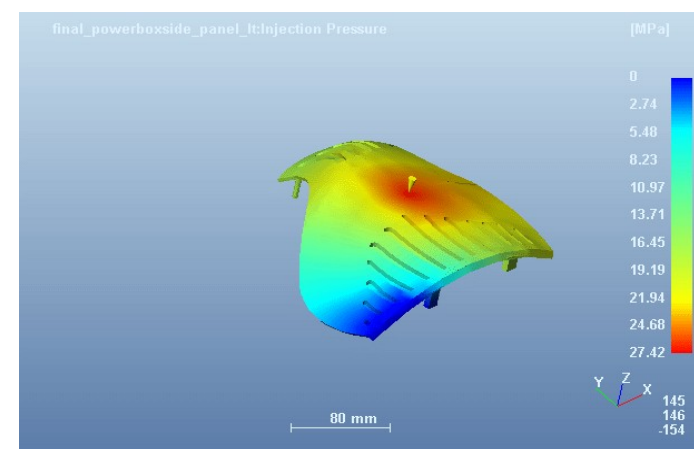

Fig. 3.4 Injection Pressure

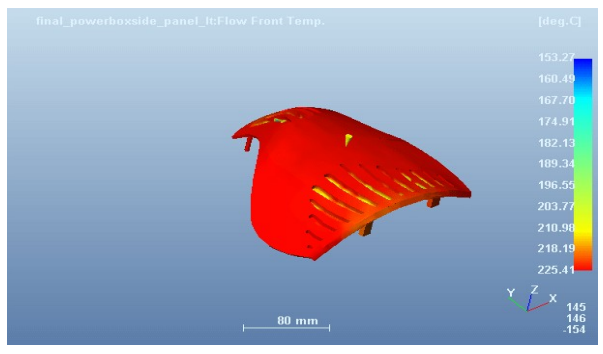

Fig. 3.6 Flow Front Temperature

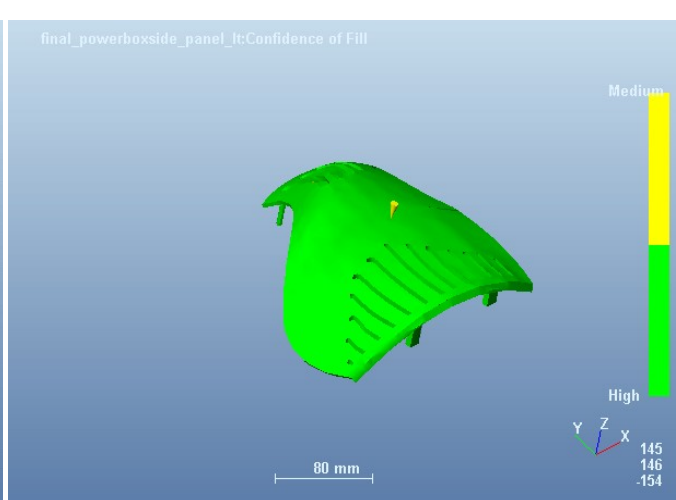

Fig. 3.3 Confidence of fill

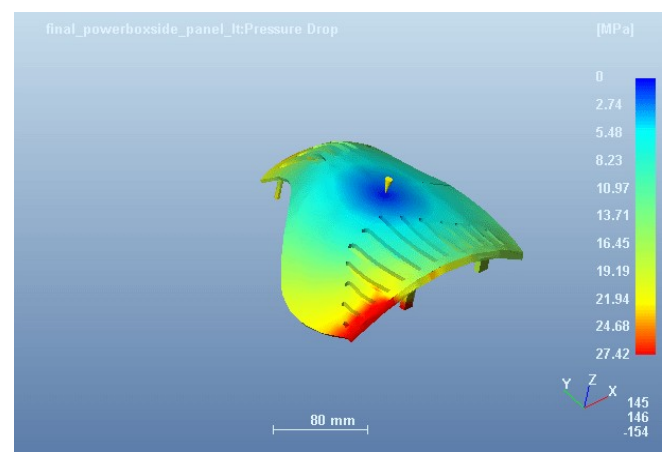

Fig. 3.5 Pressure Drop

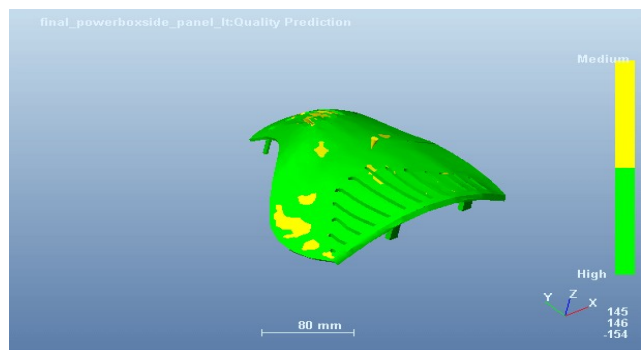

Fig. 3.7 Quality Prediction 


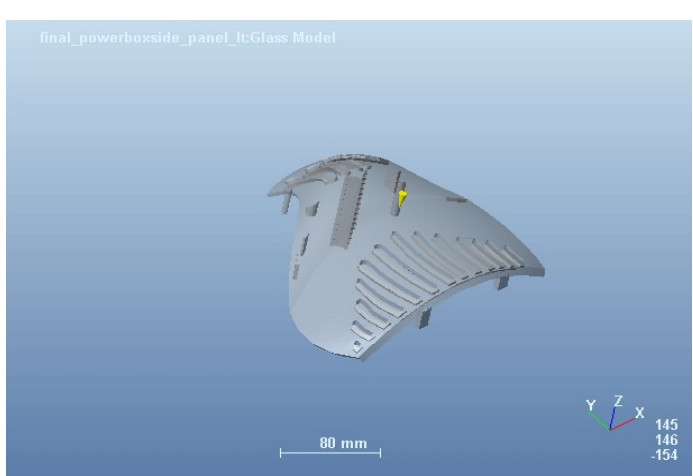

Fig. 3.8 Air Traps

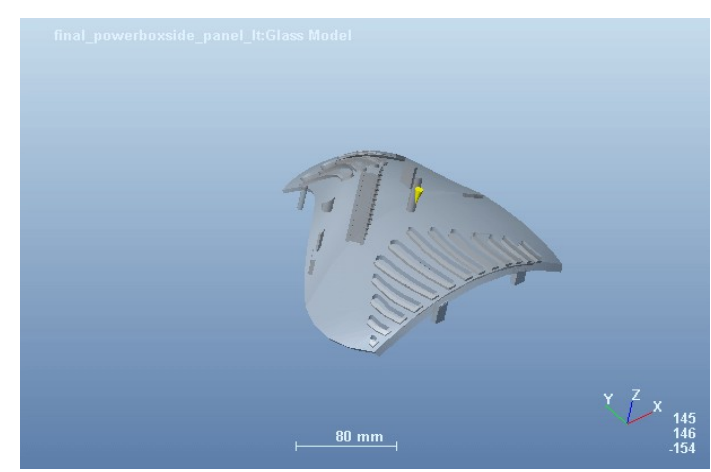

Fig. 3.9 Weld Lines

\section{Mould Calculations For Power Box}

Volume $=144592 \mathrm{cu} / \mathrm{mm}$, Surface Area $=36972 \mathrm{Sq} \mathrm{mm}$ 'Mass $=0.15 \mathrm{Kg}=150$ grams. Injection Pressure $=24.71 \mathrm{M}$ pa, Cycle time $=10 \mathrm{~s}(\mathrm{~min}$ time of ejection $)+$ fill time $=14 \mathrm{~s}$. Number of components produces per hour production $=3600 / 14=257.132$ components $/$ hour.

CLAMPING FORCE: Where $\mathrm{F}_{\mathrm{c}}=$ clamping force, $\mathrm{P}_{\mathrm{c}}=$ cavity pressure, $\mathrm{A}_{\mathrm{p}}=$ projected area, $\mathrm{N}=$ no. of cavities $\mathrm{F}_{\mathrm{c}}=\mathrm{P}_{\mathrm{c}} \times \mathrm{A}_{\mathrm{p}} \times \mathrm{N}=24.71 \times 36972 \times 1=913578.12 \mathrm{~kg} / \mathrm{s}=913.57$ tons

Considering the mechanical efficiency as $80 \%$, require machine capacity of 1216.52 tons

SPECIFICATIONS OF MACHINE: Suitable machine is 1300 tons, Mould height $=650-1300 \mathrm{~mm}$, Plunger hole diameter $=6 \mathrm{~mm}$, Plate size $=2000 \times 2000$ maximum $=350 \times 350$ minimum.

SHOT CAPACITY: Shot weight=component weight $\times($ density of PA-6/ps $)=150 \times(1.45 / 1.05)=209.76$ grams. (Where PA-6/ps is the difference between crystalline $\&$ crystallite density $=1.45 / 1.05$ )

COOLING CALCULATIONS: $\mathrm{Q}=\mathrm{Mp} \times \mathrm{ax} 5^{\circ} \mathrm{Cal} / \mathrm{hr}=255.77 \times 209.76=53650.315 \times 5^{\circ}=268251.576 \mathrm{Cal} / \mathrm{hr}$. (where $\mathrm{Mp}=$ shot weight, $\mathrm{Q}=$ heat flow per hour, $5^{\circ}$ is the temperature difference for $\mathrm{PP}, \mathrm{PC}, \mathrm{ABS}, \mathrm{HDPE}$ materials).

QUANTITY OF WATER $\left(\mathrm{q}_{\mathrm{w}}\right)=\frac{Q}{2}=268251.576 / 2=134125.788 \mathrm{Cal} / \mathrm{hr}$.

MASS OF WATER $\left(\mathrm{m}_{\mathrm{w})}=\mathrm{Q}_{\mathrm{w}} /(2 \times 0.64 \times 5)=134125.788 / 2 \times 0.64 \times 5=214.6 \mathrm{lit} / \mathrm{hr}\right.$.

( 0.5 for direct cooling used for casting, 0.64 for indirect cooling for injection molds and cold chambers)

\section{Mould Extraction}

A die is usually made in two halves and when closed it forms a cavity similar to casting desired. One half of the die remains stationary is known as "cover die" and the other movable half is called "ejector die".

The die casting method is used for castings of non-ferrous metals of comparatively low fusion temperature and this process is cheaper and quicker than permanent or sand mould casting. Most of the automobile parts are mad with this process.

5.1.1 Mould Extraction For Core and cavity Core is male portion of the mould forms the internal shape of the moulding. Cavity is the female portion of the mould, gives the moulding its external form of the part.

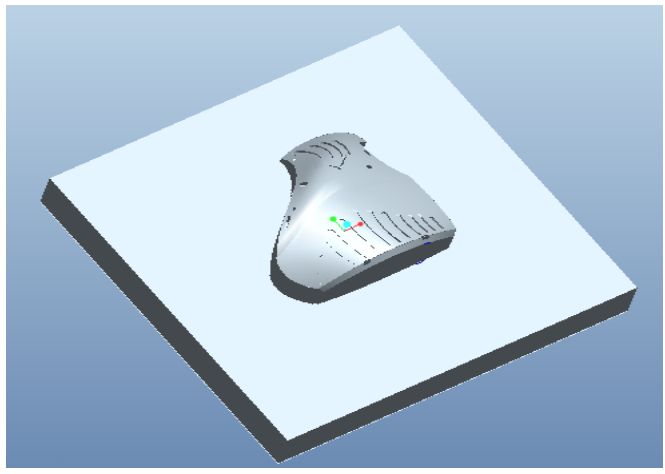

Fig.5.1 Mould Extraction for Core

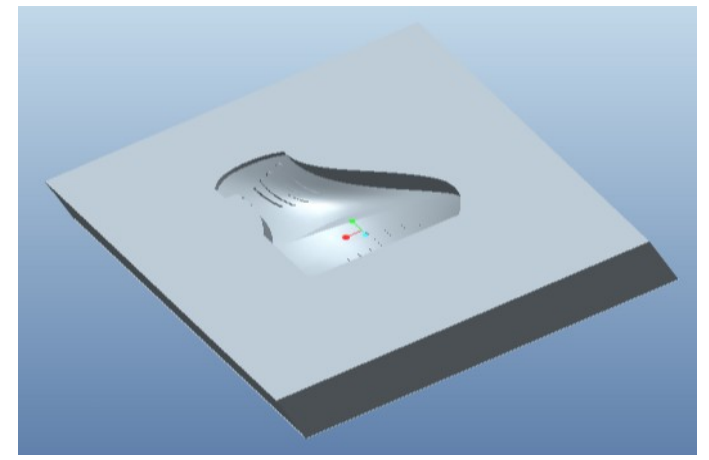

Fig.5.2 Mould Extraction for Cavity

5.1.3 Total Mould Assembly Before manufacturing the complete part model, total mould assembly has to taken by core and cavity back plate, ejector pin, ejector plate, guide pillar, guide bush, grid, retainer pin, retainer plate, spacer, back plate. 


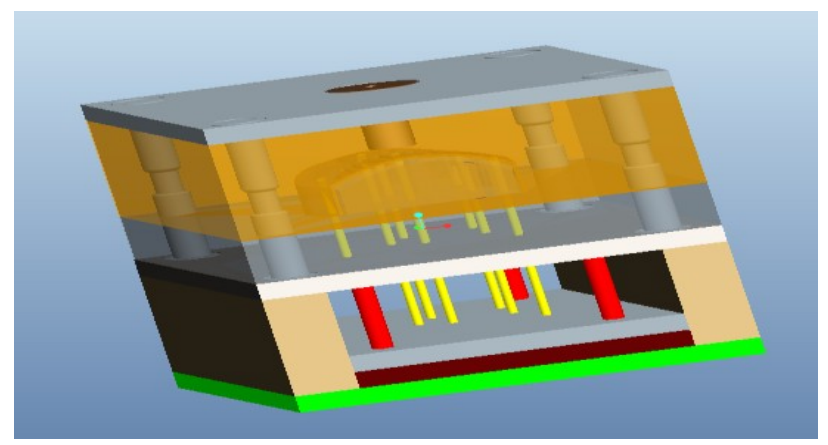

Fig.5.3Total Mould Assembly

5.2 Manufacturing Process After designing the mould tool, with the parameters now manufacturing the power box according to the dimensions. The flow chat of the manufacturing process is given as

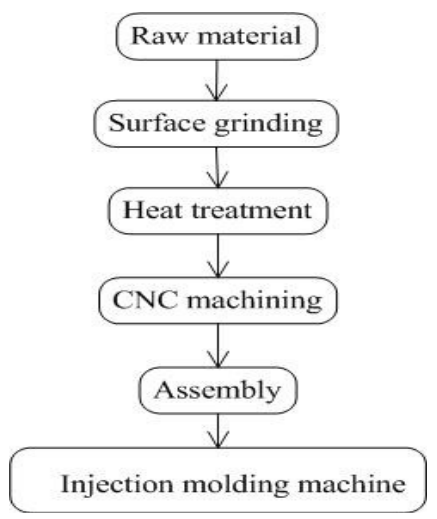

5.2.1 Manufacturing Process for Core and Cavity After the mould extraction of the part, manufacturing process has done, for work piece of core and cavity select the cutting tool bit was rough one with given dimensions such as tolerance, step over, scan type, cut type, rough option clear distance, spindle speed, coolant option and $\mathrm{CNC}$ milling operation has done to required core and cavity part before that select the play path. in Pro-E.

After completion of tool play path check the required part shape is obtained or not by using NC check

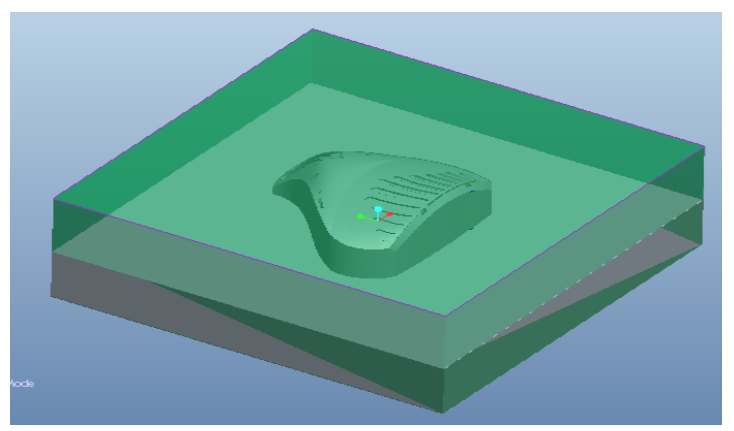

Fig. 5.4 Core Work Piece

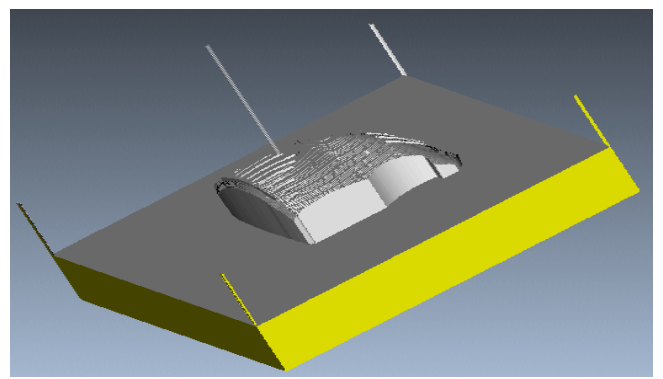

Fig. 5.6 Core NC Check

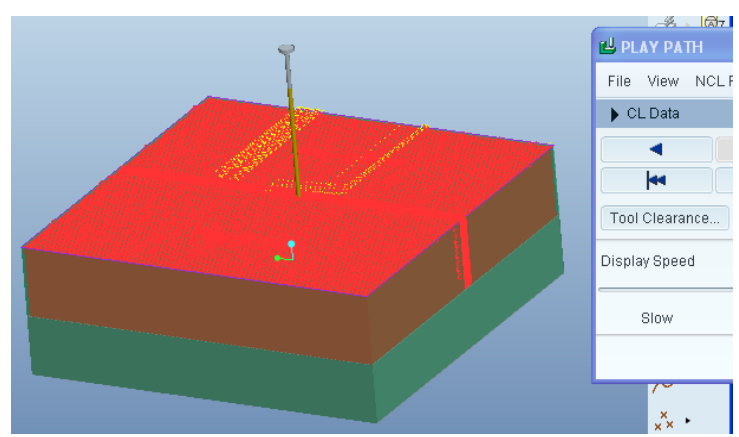

Fig. 5.5 Core Play Path

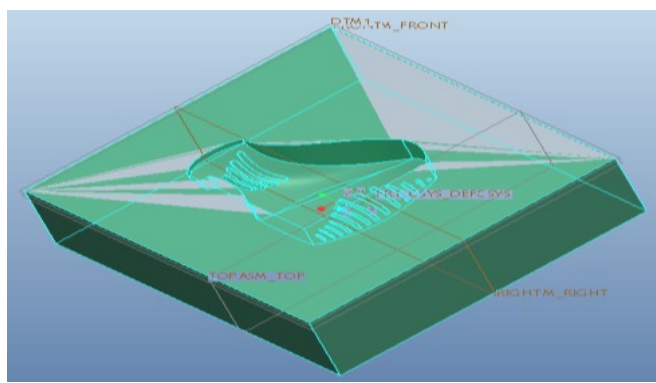

Fig. 5.7 Cavity Work Piece 


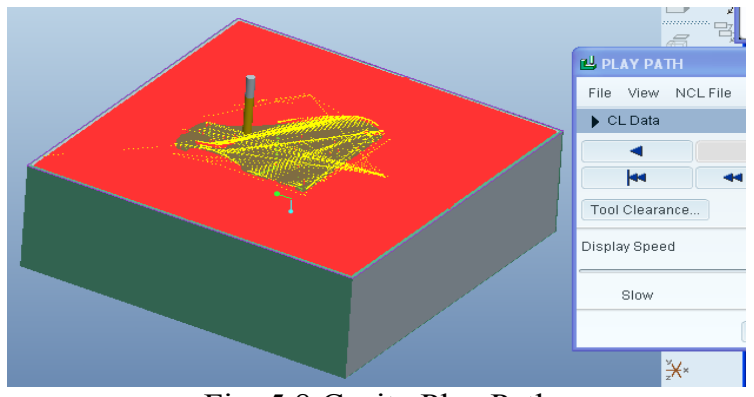

Fig. 5.8 Cavity Play Path

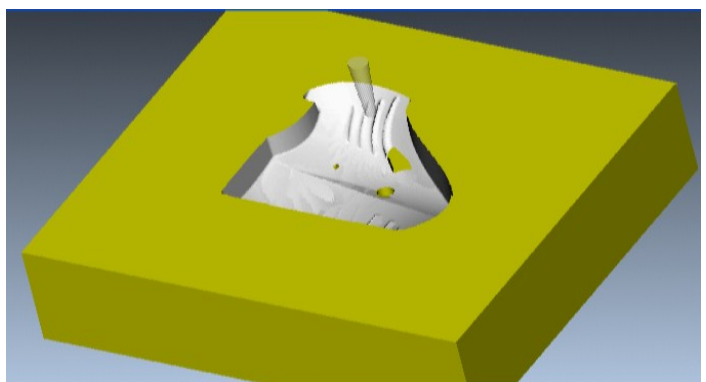

Fig. 5.9 Cavity NC check

\subsection{Finishing Operations for Core and Cavity}

Finishing operation is done for core and cavity by the given dimensions are cut feed, arc feed, plunger feed, step depth, step over, spindle speed, clear distance after the rouging operation because of better surface and to minimize the machining time. Typically, if the required part is more complex parts and greater surface finish required and also offers the saving the cost of the machining die, then go to the both roughing and then finishing operations to complete a required part component.

\section{Structural Analysis}

Here core and cavity imported from the pro-Engineer and to find the displacement, stress.

\section{Cavity:}

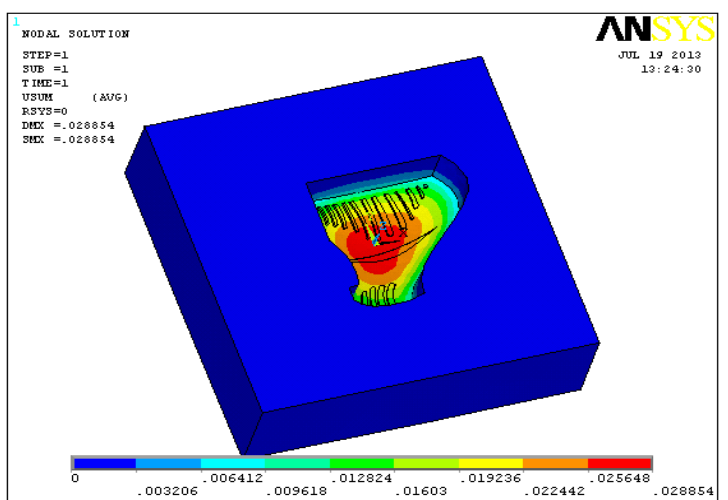

Fig.6.1 Displacement $=0.028854 \mathrm{~mm}$

Core:

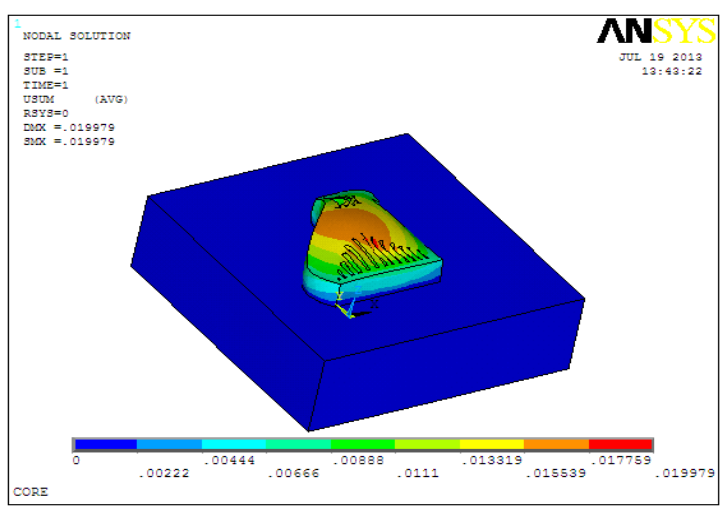

Fig.6.3 Displacement $=0.019979 \mathrm{~mm}$

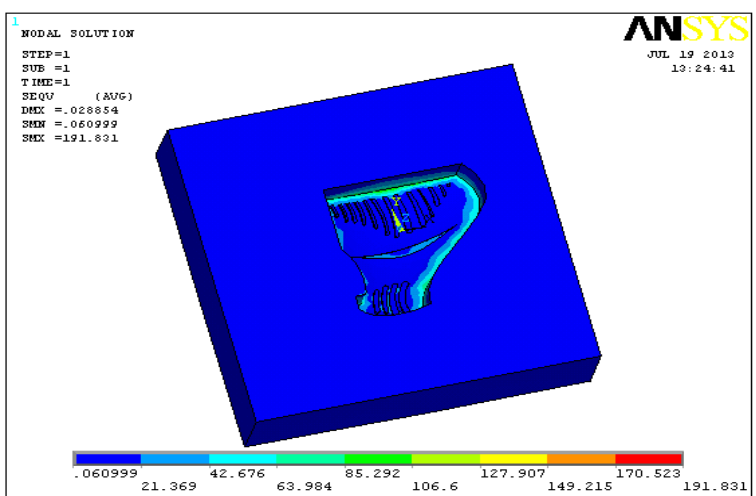

Fig.6.2 Stress $=191.831 \mathrm{~N} / \mathrm{mm}^{2}$

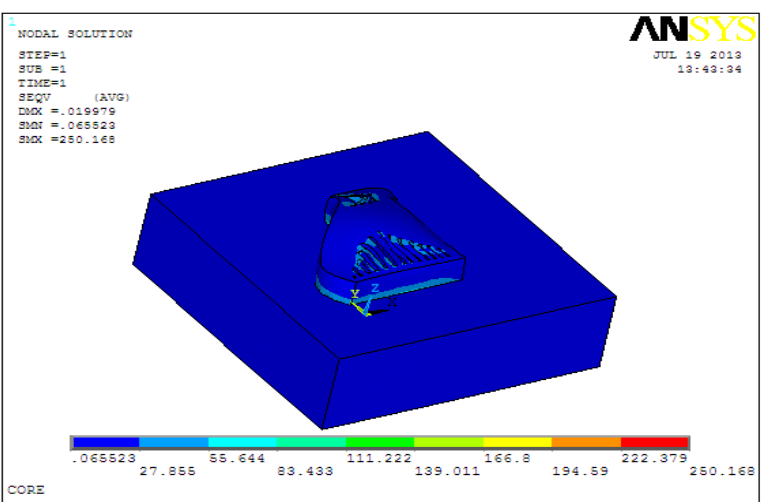

Fig.6.4 Stress $=250.168 \mathrm{~N} / \mathrm{mm}^{2}$ 
VII. Estimation Cost Of Total Die And Power Box Side Panel Component

Table7.1 Total Material Cost:

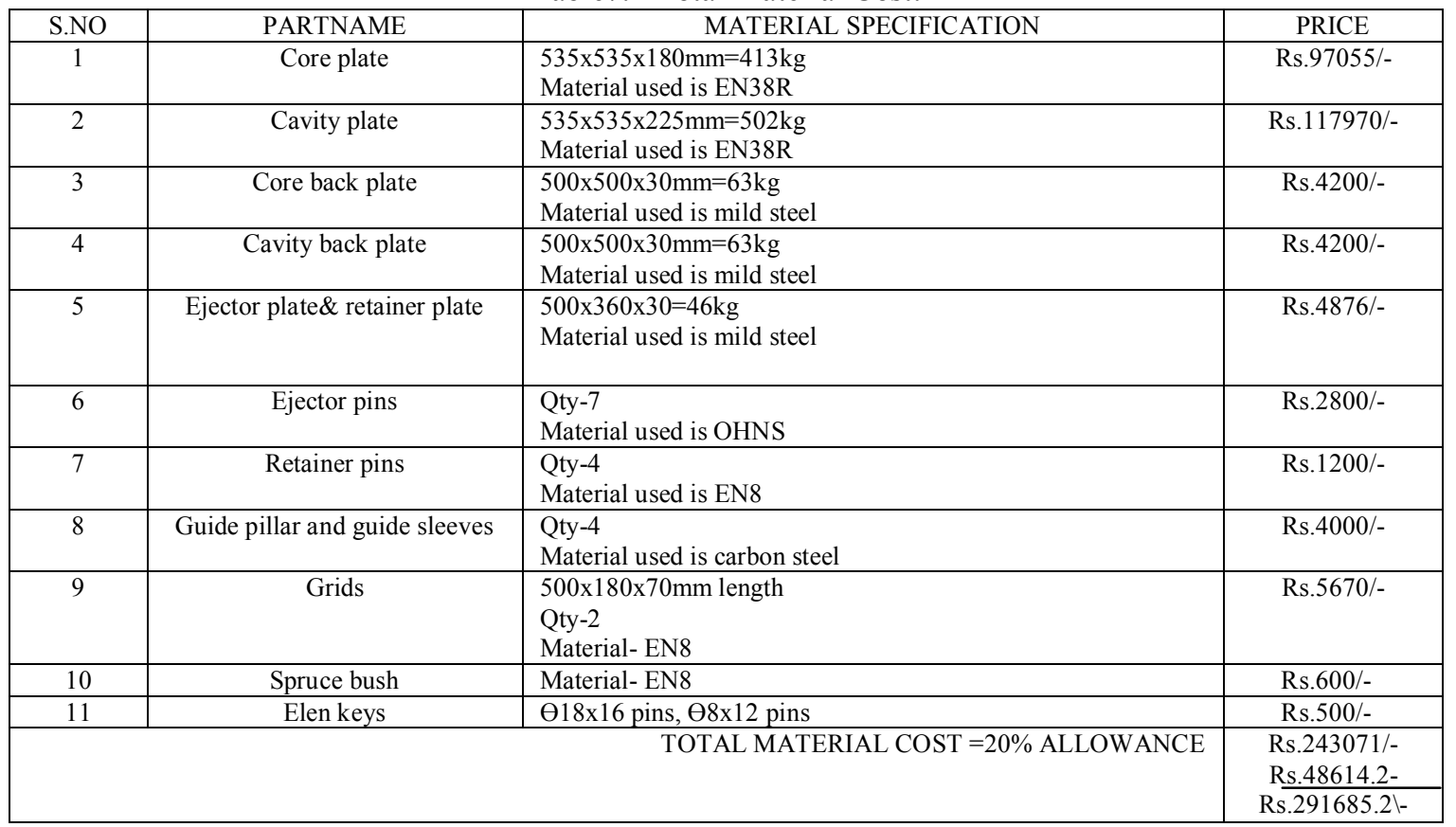

Table7.2 Total Machining Cost:

\begin{tabular}{|c|c|c|c|}
\hline S.NO & PART NAME & $\begin{array}{c}\text { MACHINIG COST } \\
\text { NO.OF hrs }\end{array}$ & AMOUNT \\
\hline 1 & Primary machining & 80 & Rs.7500/- \\
\hline 2 & Core & 90 & Rs25000/- \\
\hline 3 & Cavity & Cylindrical grinding & Rs.5000/- \\
\hline 4 & Guide pillar & Rs30000/- \\
\hline 5 & Peat treatment for core, cavity, runners, overflows & Rs.25000/- \\
\hline 6 & Polishing for core, cavity, runners & Rs.3000/- \\
\hline 7 & Chrome plating for core, cavity in pattern area & Rs. $179900 /-$ \\
\hline
\end{tabular}

\subsection{Total Die Cost}

1. Material cost

- Rs.291685.2/-

2. Machining cost

- Rs. $179900 /-$

3. Transportation

- Rs. 2000/-

4. Risk cost

- Rs.70737.78/-

( $15 \%$ of material \& machine)

5. Profit (20\% of above 4$)$-Rs. $16629 \backslash$

Total cost - Rs.108864.596/-

7.2 Estimation And Comparison Of Component Cost Using Plastic Material (Hdpe, Abs, Ps, Pc) Table7.3 Nominal values of plastic materials for injection:

\begin{tabular}{|c|c|c|c|c|c|}
\hline & $\propto\left(\frac{\mathrm{mm}^{2}}{\mathrm{~s}}\right)$ & $\theta\left({ }^{\circ}{ }_{\mathrm{C}}\right)$ & $\theta_{S}\left({ }^{\circ}{ }_{\mathrm{C}}\right)$ & $\theta_{0}\left({ }^{\circ}{ }_{\mathrm{C}}\right)$ & $\begin{array}{c}\text { COST OF } \\
\text { COMPONENT } \\
(150 \text { GRAMS Rs })\end{array}$ \\
\hline HDPE & 0.102 & $65-77$ & $30-90$ & $200-300$ & 20.028 \\
\hline ABS & 0.075 & $74-104$ & $50-71$ & $176-195$ & 20.835 \\
\hline PS & 0.077 & $75-95$ & $50-70$ & $180-210$ & 21.717 \\
\hline PC & 0.098 & $72-88$ & $62-86$ & $108-145$ & 22.905 \\
\hline
\end{tabular}

- ABS

$1 \mathrm{~kg}$ component (ABS) cost Rs138.90/-, but required component weight is 150 grams= Rs 20.835/-. Production per shift will be 7 hours $(7 \times 60 \times 60=25,200 \mathrm{~s})$ and production cost will be Rs 3500/-.

Production time $\mathrm{t}_{\text {cycle }}=\mathrm{t}_{\text {mould close }}+\mathrm{t}_{\text {injection }}+\mathrm{t}_{\text {cooling }}+\mathrm{t}_{\text {mould open }}+\mathrm{t}_{\text {ejection. }}$.

The time taken for mould (close, open) injection, ejecting are few seconds and it taken as $4 \mathrm{~s}$. 
The time for cooling $\mathrm{t}_{\text {cooling }}$ is $-0.2435{\frac{l^{2}}{\alpha}}^{2} \log \left(\frac{\pi}{4} \frac{\theta-\theta_{s}}{\theta_{0}-\theta_{s}}\right)=29.708 \mathrm{~s}$, production time $=33.708 \mathrm{~s}$.

(Where $l=$ thickness of the component in $\mathrm{mm}=3.5 \mathrm{~mm}, \alpha=$ temperature conductivity rate of component in $\frac{\mathrm{mm}^{2}}{\mathrm{~s}}, \theta=$ centre temperature of the component $\left({ }^{\circ} \mathrm{C}\right), \theta_{\mathrm{s}}=$ mould temperature $\left({ }_{\mathrm{C}}^{\circ}\right), \theta_{0}=$ initial temperature $\left({ }^{\circ} \mathrm{C}\right)$ ).

Components produced per shift $=\frac{25200}{33.708}=747.568$, Production cost per shift $=\frac{3500}{747.568}=\mathrm{Rs} 4.681 /-$

Total Cost $=$ Material Cost + Production Cost + Packing Charges + Printing Cost $=20.835+4.681+5+5=$ Rs 35.516/-

Similarly the Total Cost of ABS, PS, PC are calculated based on the above table relations

HDPE Total Cost $=$ Rs36.035 /-, PS Total Cost $=$ Rs 36.777/-, PC Total Cost $=$ Rs 37.886/-

- Comparison of Cost and Plastic Materials

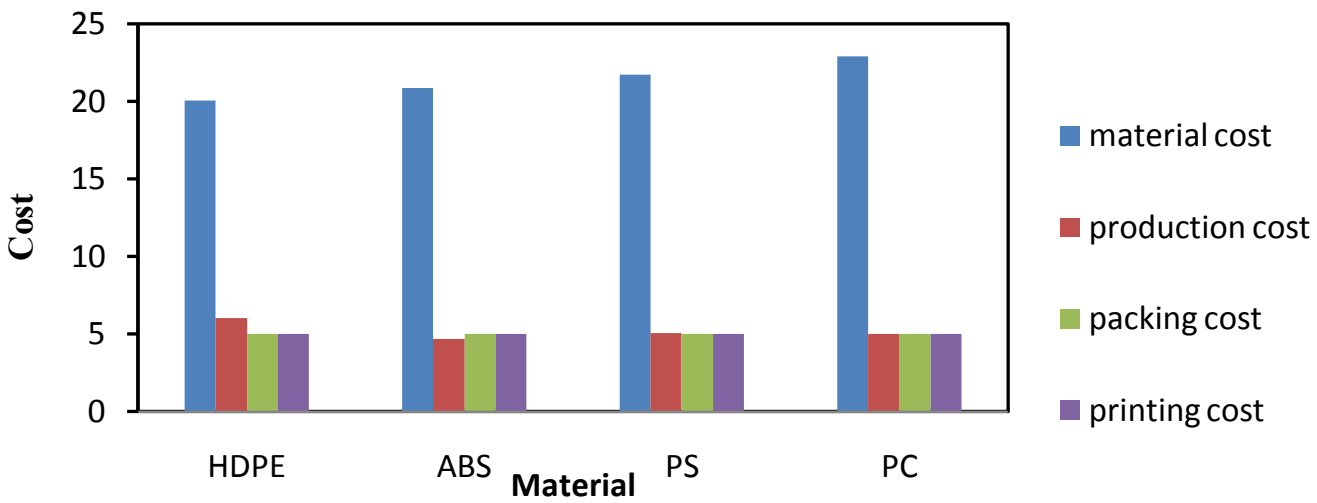

Fig.7.1 Cost verses Individual plastic materials

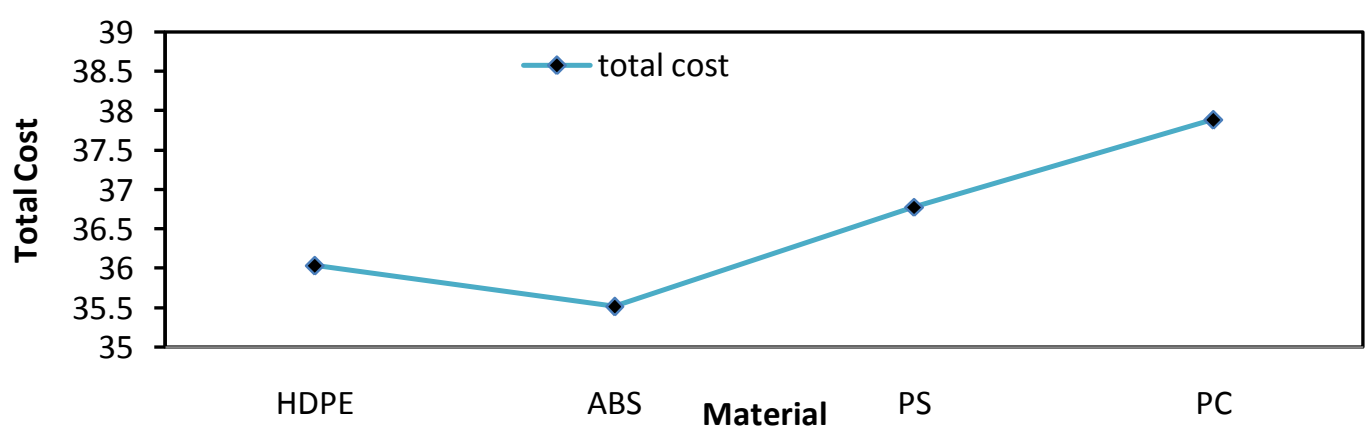

Fig.7.2 Total cost verses Individual plastic materials

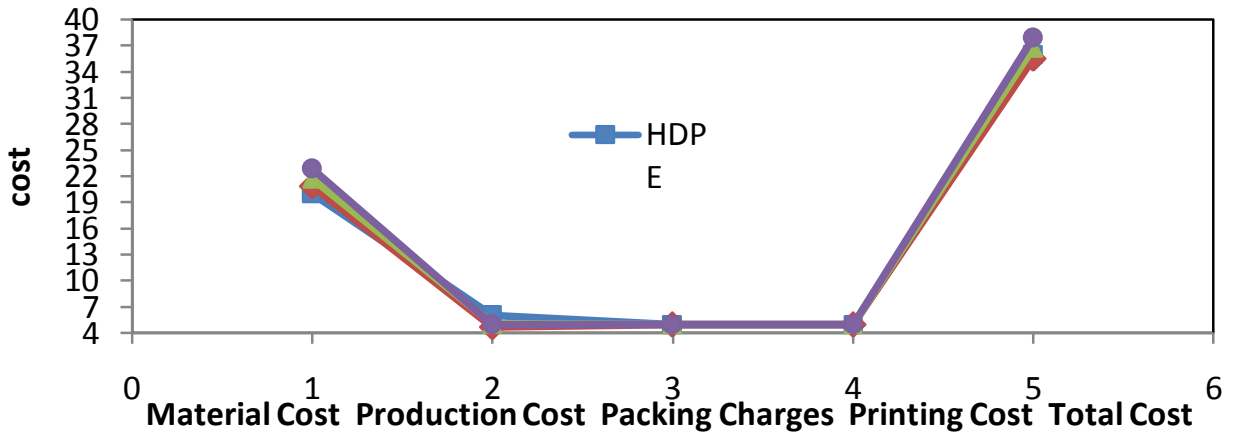

Fig. 7.3 Combination of Individual and Total Cost

VIII. Conclusion

In this paper, power box side panel which is used in earth movers is designed. The modeling of component, Core-Cavity design and mold flow analysis is done in Pro/Engineer wild fire 5.0The component according to standards by providing shrinkage allowance $1.25 \%$, draft angle 1 deg along core side and $1 \mathrm{~mm}$ radius in all sharp corners are provided. For above designed model, the complete mould base for side panel is 
design. The machine, runner design, over flow design, cooling channel design is also selected. CNC programming is generated for core and cavity.

Cost of total die assembly and cost Comparison of power box side panel component with different plastic materials such as (HDPE, ABS, PP, and PC) and cost per each piece are estimated. Among these materials ABS is best material for manufacturing of injection moulding die because of the total cost of the material is less. Structural analysis on core and cavity by applying clamping force is done. The material used is EN31B Steel. By observing the analysis results, the stress values are obtained for both core and cavity are less than the yield stress value of EN31B. So by using material EN31B for die can withstand the forces.

This work is useful for making complete injection mould tool design for the power box side panel.

\section{References}

[1] Georg menges, Hans Pecker "Computer Aided Engineering in Injection molding" Journal on comprehensive polymer science \& Supplements, vol .71989 .Pages 451-488.

[2] Millers and Pedgen D, 2000, "Introduction to Manufacturing Simulation", Proceedings of the 2000 winter simulation conference PP 63-66.

[3] A.H.S.Park ,X.P.Dang, A.Roderburg, "Development of Plastic Panels ” CIRP Journal of Manufacturing \&Techonology vol 26 Pages 35-53.

[4] Alan.R.Grayer, "Alternative approaches in Geometric modeling”, Journal on CAD, volume 12, issue 4,july 1980, pages 189-192.

[5] Erh Guoliangxu, "Mixed Finite Element Methods for Geometric modeling using $4^{\text {th }}$ order geometric flows. "Journal on Computer Aided Geometric Design". vol 26, issue 4, may 2009,Pages 378-395.

[6] E.G.Gottstain, M.Goerdeler, G.V.S.S Prasad "Mechanical Properties :Plastic Behaviour" Journal on Encyclopedia of condensed matter of Physics"2005 Pages 298-305.

[7] C.Khan molek. L.Robert,A.Singh . "High Resolution Thermo plastic Rapid Manufacturing using Injection Moulding". CIRP Journal of Manufacturing science and technology, volume 4, issue 4 2011, Pages 382-390.

[8] E.Maine, M.F.Ash by "Material selection \& Mechanical Design "Journal on Encyclopedia of Material ,Science \&Technology $2^{\text {nd }}$ edition pages 53-83.

[9] M.zakria Baig, "Industrial Engineering Estimating \&Costing”, Radiant Publishing House

[10] Japan.s.Daniel.L. and Theodor .k.2005. "Finite Element Analysis of Beams", Journal of Impact engg. vol 31, Pages 861-876.

[11] Peacock AJ (2000) Handbook of polyethylene. Marcel Dekker: 13-30.

[12] Elias, Hans-Georg. (2003).An Introduction to Plastics. Weinheim: Wiley-VCH GmbH \& Co. KGaA.

[13] Antunes, M.; Velasco, J.I.; Realinho, V. \& Solorzano E. (2009). Study of the cellular structure heterogeneity and anisotropy of polypropylene and polypropylene nanocomposite foams. Polymer Engineering and Science. Vol.49, No.12, pp. 2400-2413, ISSN 1548-2634.

[14] S Huang, H.-X.; Wang, J.-K. \& Sun, X.-H. (2008). Improving of Cell Structure of Microcellular Foams Based on Polypropylene/High-density Polyethylene Blends. Journal of Cellular Plastics, Vol.44, No.1, pp. 69-85, ISSN 1530-7999.

[15] S R.T. Moura, A.H. Clausen, E. Fagerholt, and M. Alves. Impact on HDPE and PVC plates - Experimental andnumerical simulations. Int. J. of Imp. Engng., 2010. in press.

[16] Lei, Xie ; Gerhard, Ziegmann . (2009) Influence of processing parameters on micro injection molded weld line mechanical properties of polypropylene, Microsystem Technology, 15, pp 1427-1435 .

[17] Lee ,K.S; Lin, J.C. (2006) Design of the runner and gating system parameters for a multi-cavity injection mould using FEM and neural network, , International Journal of Advanced Manufacturing Technology, vol.27,pp. 1089-1096.

[18] Raviwongse ,Rawin; Allada., Venkat; (1997) Artificial Neural Network Based Model for Computation of Injection Mould Complexity ,International Journal of Advanced Manufacturing Technology , 13, pp. 577-586.

[19] Jan, T. C. and O'Brien, K. T. (1993) A user-friendly, interactive expert system for the injection moulding of engineering thermoplastics.International Journal of Advanced Manufacturing Technology, 8, 42-51.

[20] Chen, B. S. and Liu, W. H., "Numerical simulation and experimental investigation of injection mold filling with melt solidification", Polymer Eng. and Sci. 29 (1989) 1039-1050.

[21] Pandelidis, I. O. and Kao, J.-F. (1990) DETECTOR: a knowledge-based system for injection molding diagnostics. Journal of Intelligent Manufacturing, 1, 49-58.

[22] Shi,F; Lou,Z. L.; Lu ,J. G. and Zhang Y. Q. (2003), Optimization of Plastic Injection Molding Process with Soft Computing operations ,International Journal of Advanced Manufacturing Technology ,21,pp.656-66.

[23] P. Postawa, J. Koszkul, Influence of processing conditions on changing of shrinkage and mass POM injection molding parts, Proceedings of the 13th Scientific International Conference, Achievements in Mechanical and Materials Engineering, AMME'2005, Gliwice-Wisáa, 2005, 531-534.

[24] Mathivanan D. ; Parthasarathy, N. S. (2009).Prediction of sink depths using nonlinear modeling of injection molding variables, International Journal of Advanced Manufacturing Technology, vol. 43 pp.654-663. 